\title{
Plenty of room for improvement
}

\author{
C. N.R. Rao describes the difficult situation that Indian education is facing and provides some suggestions \\ on how things can get better.
}

$\mathrm{T}$ he education scenario in India is extremely complex at all levels. There are several higher educational institutions supported by the central government, but their quality varies substantially and only a few of them can be considered high quality. Additionally, there are numerous universities supported by the different states and several privately funded institutions. Funding of most of the institutions in the country has been inadequate for a long time, especially in the case of state-supported ones. At the same time, the demand for education has been increasing, and this has led to many of the private institutions to behave almost as commercial enterprises. Colleges for engineering, management and other disciplines have mushroomed across the cities, often offering courses without adequate facilities and qualified teachers.

The situation is even worse for school education, both at primary and secondary level. There are expensive schools and special academies in the cities for those who can afford them, but most schools are in poor conditions. This is especially true in rural India, where most children still live, and where it is common to find singleteacher schools. The general situation is appalling, especially considering that India has a very young population, with a high percentage of citizens below the age of 25 .

The budget for education has increased only marginally in the past few decades. Since 1990, the various governments have promised that $6 \%$ of the gross domestic product will be invested in education with at least $2 \%$ going towards higher education, but this promise has never been kept. Such poor investment, as well as the bureaucratic control and political interference have affected the performance of state-supported institutions and generated the great disparity in education quality.

We should also keep in mind that good education is strictly connected to highquality research and innovation. Universities have been the main contributors of scientific research in India in the past. Today, however, most of the scientific output originates from research-only institutions, with marginal contributions from universities. India has to increase the quantity of scientific research by publishing more papers. The country should aim to contribute around $10 \%$ to world research (instead of $\sim 3 \%$ today). More importantly, the quality has to improve substantially. The highly competitive atmosphere created by the neighbouring countries in Asia is making great demands on India, which should aim to publish 5-10\% (instead of 1\% today) of the top $1 \%$ of world research in the next 10 years.

There are a few good research institutions, supported by the science departments of the Indian government, which offer postgraduate programmes. The Tata Institute of Fundamental Research (supported by the Department of Atomic Energy) and the Jawaharlal Nehru Centre for Advanced Scientific Research (supported by the Department of Science and Technology) are outstanding research centres with only $\mathrm{PhD}$ students. The laboratories of the Council of Scientific and Industrial Research have around 2,500 $\mathrm{PhD}$ students, and the Indian Institute of Science in Bangalore, which is the oldest and probably one of the finest institutions in the country has around $1,300 \mathrm{PhD}$ students, it also started a highquality undergraduate programme around 3-4 years ago. Unfortunately, these are rare cases, in reality the number of institutions offering high-quality education and research opportunities at the postgraduate level is small. This is why highly qualified young Indians, many of whom go abroad after graduating, find it difficult to find the right kind of position to work in India. It is embarrassing that there are no Indian universities in the top 100 in the world rankings.

Things need to improve and to progress we need to take the few successful institutions at all levels of education as model systems. In rural India, we should have many more well-endowed schools, similar to Jawahar Navodaya Vidyalayas, which are residential schools that provide full support for the education of talented young pupils. At the higher-education level the establishment of five new Indian Institutes of Science Education Research, which provide outstanding science education for undergraduates and research opportunities for postgraduate students, has been a tremendous success. The Indian Institutes of Technology are already excellent for undergraduate education in engineering, although to really flourish they have to improve their contribution to research, development and innovation. Also, at present, most universities expend substantial effort in providing examinations to thousands of undergraduate students studying in affiliated colleges, and this detracts from providing high-quality education. Efforts to improve our universities, both through investments and structural reforms would be a major task of the newly elected government.

An essential aspect that must change is the attitude of people towards education. Teaching needs to become a high societal value, because only through demands from the public will the government and the education system feel the pressure to change for the better.

At present, there are programmes for scholarships and other incentives for talented students, but these are simply not enough, especially considering that in the next 20-30 years, India may have an additional 10-20 million children in need of high-quality education. The country needs a massive upgrade in the quality of the institutions and in the opportunities for young people. It is essential that in democratic India with a vast population, school education is sound and instils scientific temper in young people. In my opinion, the government should have a national mission that is focused on improving education standards and employment opportunities for the millions of young people. If the right investments are made in science and education, I see no reason why India cannot emerge as a major global player.

C. N. R. RAO is a National Research Professor, Linus Pauling Research Professor and Honorary President of the Jawaharlal Nehru Centre for Advanced Scientific Research, Jakkur PO Bangalore 560 064, India. e-mail: cnrrao@jncasr.ac.in 